International Review of Research in Open and Distributed Learning Volume 18, Number 1

February - 2017

\title{
Properties of Teacher Networks in Twitter: Are They Related to Community-Based Peer Production?
}

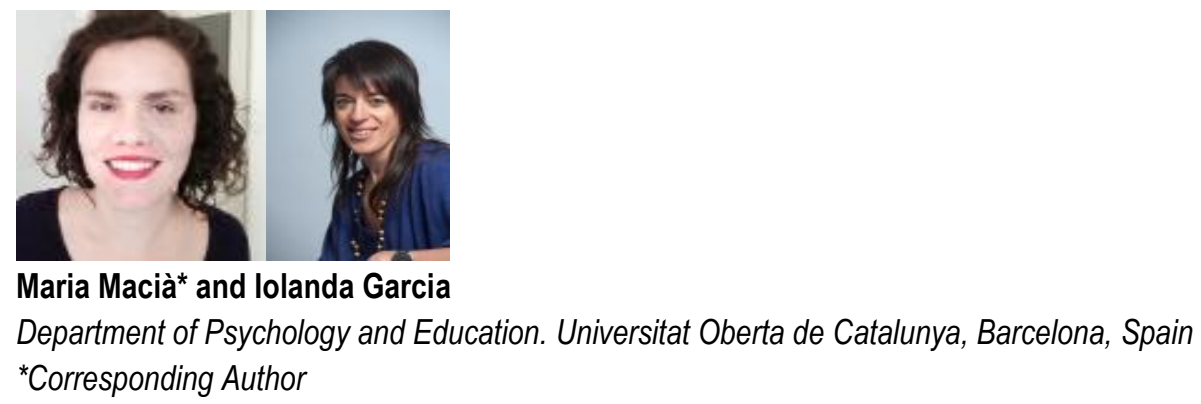

\begin{abstract}
Teachers participate in social networking sites to share knowledge and collaborate with other teachers to create education-related content. In this study we selected several communities in order to better understand the networks that these participants establish in Twitter and the role that the social network plays in their activity within the community, especially related with peer production. We analyzed the topology of these networks in two ways: a) the indirect relations by counting followers and followed people; and b) the conversational networks by counting mentions in tweets. We also analyzed the communities' websites in order to elucidate whether their production was lightweight or heavyweight peer production. Results indicate that teacher networks adopt a community clusters archetype in which some teachers act as bridges between several groups. Although these networks do not form a tight crowd, their degree of tightness is superior to that of the general networks established in Twitter. Our results also indicate that the degree of tightness is important for sustaining heavyweight peer production and strong leadership can play a crucial role in establishing long-term commitment to a collective task.
\end{abstract}

Keywords: online social networks, teachers' professional development, network topology, open learning, peer production, virtual communities, bridging role, Twitter

\section{Properties of Teacher Networks in Twitter: Are They Related to Community-Based Peer Production?}

Teachers in search of new ideas and willing to try new methodologies and resources often look for support outside the school and other regulated teacher training channels. Online networks and communities offer these teachers the opportunity to share knowledge and learn with other peers located far away from each 
other and who belong to other contexts and teaching realities (Ravenscroft, Schmidt, Cook, \& Bradley, 2012), and thus they are an exceptional source of ideas, resources, and information for each other. Teachers use these online spaces to share experiences, knowledge, and materials, as well as to provide each other with emotional support, develop collective projects, offer skills training, and, for a minority, also to collaborate in creating educational production (Macià \& García, 2016). Teachers' informal use of social networking sites for professional purposes has been studied in the case of Twitter (Davis, 2015; Smith Risser, 2013; Wesely, 2013), Facebook (Ranieri, Manca, \& Fini, 2012), and Ning (Coutinho \& Lisbôa, 2013). Among the aforementioned online networks, Twitter is of special interest because many teachers are present in this network and use it to share experiences and reflect on practice, to pose or ask questions, to share teaching materials and resources, to hold generic discussions, and to provide emotional support (Davis, 2015; Smith Risser, 2013; Wesely, 2013). In general, people tend to use Twitter to write posts about themselves, whereas educators tend to use it to share information (Forte, Humphreys, \& Park, 2012). For this reason, Twitter can become an aggregator of content or resources present in other social networks or virtual sites (Wesely, 2013) as teachers tweet the link to this content and it can be recovered through the use of a hashtag (the method used in Twitter to categorize tweets into topics).

Twitter is a microblogging service that enables users to send 140-character messages called tweets. Users can follow other members or be followed, but there is no need to establish a reciprocal relationship. Members can read all the tweets posted by the people they follow. These messages can contain links, and also direct mentions to other members (placing an @ in front of the user name) or topics of interest called hashtags (placing a \# in front of the topic name). Users can replicate any message of their interest in their tweet line (this action is called retweet), thus expanding the possibilities of information sharing beyond of the initial reach of the author's followers.

Teachers appreciate Twitter because it is interactive, user friendly, immediate, connects them to other colleagues, and offers them personalized professional development opportunities (Carpenter \& Krutka, 2014, 2015). They perceive the tool as an online forum for exchange with other professionals and also to reflect on practice (Davis, 2015; Wesely, 2013). Teachers using Twitter are technology early adopters, often act as bridges and try to incorporate the information learned in the networks into their school environments (Forte et al., 2012). These same teachers often mention a feeling of loneliness experienced in their schools which they offset by participating in online social networking sites (Davis, 2015; Wesely, 2013). However, according to Forte et al. (2012), these teachers could play an active role in training their colleagues and in generating educational change in schools. As has already been shown, participation in online communities and networks has positive effects on professional development, such as gaining new insights into teaching practice or furthering inquiries into new methodologies, resources, or educational theories (Macià \& García, 2016). Thus, it is important to gain further knowledge about how participation in environments such as Twitter are developed, how it can influence peer production and professional development, and what impact it may have on teachers' school practices.

Twitter can be considered as a network (directed graph) as it connects distributed people, either directly or indirectly. According to Dron and Anderson (2009), networks have undefined limits and their characteristics change quickly. Wenger, Trayner, and de Laat (2011) defined a social network as "the set of 
relationships, personal interactions, and connections among participants who have personal reasons to connect" and contrasted this definition with the one of community which is "the development of a shared identity around a topic or set of challenges" (Wenger et al., 2011, p. 9). Participation in a network provides access to a wide range of information flows that can be useful for obtaining resources, finding solutions, or establishing dialogues in targeted or untargeted searches (Wenger et al., 2011). In contrast, within a community, learning is focused on advancing the knowledge of the shared domain, which is nurtured by a common history of learning, shared practices, and the commitment to negotiate, learn, and develop ideas and resources together (Wenger et al., 2011). The commitment required to participate in a community should be high and sustained, whereas participation in a network can be spontaneous, unpredictable, and serendipitous. Although both structures can exist independently, it is common to find them combined in the same group (Macià \& García, 2016). For instance, a group of teachers at the same school may be a community as they share an identity and collaborate formally or informally to develop shared practices, but they might also form a network as they exchange information and resources among them. Moreover, teachers at the school might be part of other networks at the same time, thus providing additional information that can be beneficial for the school learning.

In the case of network structures, it is important to be connected to as many peers as possible in order to have access to the information flow. In recent literature, online teachers' networks are mainly described through social capital theories and social network analysis, which reveal how the information flows between a group of network members (Ranieri et al., 2012; Schlager, Farooq, Fusco, Schank, \& Dwyer, 2009; Smith Risser, 2013; Tseng \& Kuo, 2014). The study of a network structure enables researchers to detect weak ties between participants and bridging roles (Granovetter, 1983, 1973). Weak ties between participants and bridging roles play a crucial role in disseminating information across the network, as shown in a study conducted by Schlager et al. (2009). In this study, teachers belonging to more groups posted more content and participated more in the synchronous and asynchronous conversations.

Participants in the above-described networks are sometimes involved in peer production of teaching materials or other education-related materials. The collaboration between unknown members of a network or a community can adopt two patterns: lightweight peer production or heavyweight peer production (Haythornthwaite, 2009). Lightweight peer production consists of minimal contributions to a more general project. These contributions are well defined and are quick to provide, avoiding the need for participants to make a long-term commitment to a project or to establish relations with other participants. The heavyweight peer production model involves interdependence between members and the commitment to sustain the product and also the community, which makes the product possible. Participation in this kind of production requires investing a great deal of time in fostering the community dynamics, setting rules, and building the community operational structures and the product. These two models, the lightweight and the heavyweight, are two edges of a spectrum that can be found in the same project adopted by different members. For example, in the case of teachers' communities with a website, a group of teachers could be involved in sustaining the web structure, in developing the rules of participation and in searching for contributions, whereas other teachers could participate by writing a single blog post. In this study we seek to discover whether the networked relations that community members may maintain in Twitter are related to the model of peer production established in the groups or communities of reference. 
In order to analyze how the members of a community interact within a network, we collected data from members of different teacher communities participating in Twitter. This data consisting of profiles, followers and followed, and tweets can provide information on how the selected teachers interact in a network such as Twitter and thus about the characteristics of network interaction for teacher professional development purposes. This analysis also proved useful for exploring connections and mutual influences between the network and the community structure. Additionally, we gathered data about the network participants' peer production on their communities' website on the basis of the registered contributions of their members, in every case with the aim of analyzing the relationship between the topology of a specific network and the production pattern of the corresponding community.

\section{Research Questions}

The purpose of this study is to analyze the characteristics of the networks established in Twitter by the members of several teachers' communities in order to elucidate the topology of these networks (i.e., how the network elements are distributed and what the flow of information within the network is). The research questions are:

RQ1. What are the properties of teachers' networks in social networking sites and how is information shared within them?

RQ2. Do teachers' networks have particular properties and characteristics compared to general population Twitter networks?

RQ3. What kind of Twitter profile do teachers who participate in more than one community have (i.e., who act as bridges)?

RQ4. Is it possible to identify any relationship between the properties of the studied networks and a peer production pattern in the communities of reference?

\section{Methodology and Methods}

In this study, network science has been applied to the analysis of a social network (i.e., Twitter) with the aim of studying the members of the networks (nodes) and the established relations (edges) of a group of teachers belonging to different virtual communities who participate in Twitter. We used data mining to obtain data from Twitter, followed by statistical analysis and also information visualization techniques in order to elucidate network properties. Two kinds of Twitter networks have been studied, one formed of direct relations and one formed of indirect relations. The data gathered from the tweets, consisting of the users who directly mention another member in a tweet, provided information for building the direct relations network. The indirect relations were extracted from the data provided by the members' profiles, which indicate who is following who. These indirect relations indicate that the nodes (users) have information about each other but do not interact.

Several network properties have been taken into account to describe the network topology: 
- Number of nodes: the number of participants in the network, which indicates the size of the network.

- Clustering coefficient: a measure of the degree of tightness in a network. The cluster coefficient can be calculated for a single node, indicating the degree of embeddedness of the node with other nodes, and for a whole network indicating the clustering of the network.

- Network diameter: indicates the longest of all the calculated shortest paths (i.e., minimal path between two nodes) in a network and is representative of the linear size of a network.

- Average shortest path length: represents the number of steps it takes to go from one member in the network to another.

- Average number of neighbours: indicates the average connectivity of a node in the network.

- Closeness centrality: indicates how central a node is in a network.

- Betweenness centrality: indicates the amount of control that a node has over the interactions of other nodes in the network. This parameter is useful to identify nodes that act as bridges.

- In-degree distribution: indicates the number of incoming edges that node has.

- Out-degree distribution: indicates the number of outgoing edges that a node has.

- Network cluster analysis: identifies sub-networks in a general network.

The above parameters provided valuable information on network topology and information flow. Additionally, we gathered further information through other means such as the Twitter profiles of the teachers and the analysis of the communities of reference websites in order to complement and better interpret the information provided by the network exploration.

\section{Participants}

Participants in this study were selected on the basis of their membership in one or several previously identified online teachers' communities. We first selected the communities, object of study, and later extracted the lists of Twitter users participating in these communities.

In order to ensure the necessary characteristics for the target of the study, we determined a number of inclusion criteria for the initial selection of the online communities: a) communities must be active during the school year 2013-2014; b) they should be informally promoted and maintained by teachers; c) virtual activity should be frequent and constant over time as well as essential for the community's life (although this could be combined or complemented with face-to-face activity); d) they should have a minimum of 30 participants; e) more than $40 \%$ of the members must be active Twitter members; $f$ ) the domain should be related with education or educational innovation; g) a minimum of $80 \%$ of the members must be primary or secondary teachers; h) the original founders should be teachers working in Spain; and i) the list of members' names is public or easy to track. 
By limiting the selected communities to medium and large Spanish online teachers' communities, most of them present in Twitter, we ensured better conditions for comparison as variability factors between communities are reduced.

To select the communities, a search was done through social networking sites and, also, three highly active teachers in the field of educational innovation were informally consulted. This search resulted in a list of 39 teachers' communities, which had presence on Twitter. After verifying the fulfillment of the inclusion criteria, only nine communities were selected, named as follows: Books, Apps, Tools, Sound, Music, Film, Art, Words, and Robot. In order to preserve participants' anonymity we have replaced the real name of each community with a code related with the community domain.

The communities selected range from 33 to 179 participants and their domains are diverse (see a broader description in Table 1). The participants in the study are all the teachers who belong to the selected communities and own a public Twitter account.

Table 1

Characteristics of the Selected Communities

\begin{tabular}{|l|l|l|l|}
\hline Community code & Domain & N. of participants & N. of Twitter users \\
\hline Books & $\begin{array}{l}\text { Teachers collaborating to } \\
\text { create digital books. }\end{array}$ & 179 & 116 \\
\hline Apps & $\begin{array}{l}\text { Information about apps and } \\
\text { mobile learning projects. }\end{array}$ & 40 & 40 \\
\hline Tools & $\begin{array}{l}\text { Use of web 2.o for educational } \\
\text { purposes. }\end{array}$ & 59 & 58 \\
\hline Sound & $\begin{array}{l}\text { Use of mobile learning to make } \\
\text { projects related to sound. }\end{array}$ & 55 & 25 \\
\hline Music & $\begin{array}{l}\text { Projects and activities related } \\
\text { to music. }\end{array}$ & 51 & 26 \\
\hline Film & $\begin{array}{l}\text { Sharing reflections and } \\
\text { activities around a film. }\end{array}$ & 33 & 22 \\
\hline Art & $\begin{array}{l}\text { Activities and projects on arts } \\
\text { at school. }\end{array}$ & 88 & 56 \\
\hline Words & $\begin{array}{l}\text { Activities, projects and } \\
\text { resources on literature and } \\
\text { literacy. }\end{array}$ & 69 & 46 \\
\hline Robotics and code learning in \\
the classroom.
\end{tabular}


Some of the participants were members of two or more of the studied communities, for this reason the total amount of Twitter participants is 342 , inferior to the sum of participants in all the communities. We had to exclude nine Twitter profiles, which were private, so the final number of participants was 333 teachers belonging to nine communities.

\section{Data Sources and Data Collection}

Data was collected from two main sources: Twitter and the communities' websites. The data extracted from Twitter consisted of a) the participants' profile; b) participants' relations; and c) participants' tweets. Later, we analyzed the communities' websites to identify their domain and count the number of publications.

In the case of Twitter, data was collected using several data mining methods. The information was extracted from the Twitter Application Programming Interface (API) which was consulted on August 2014 in order to extract: a) the participants' profile; b) participants' relations; and c) participants' tweets. The information was extracted using the TwitterR package (Gentry, 2013) for the R Project (Gentleman, Ihaka, Bates, \& others, 1997).The information obtained from the communities' websites was collected through direct observation and analysis by browsing them as they all were open accessible.

\section{Data Analysis}

The analysis of the data obtained from the Twitter extraction had two main phases: the first involved obtaining members' indirect relations (followers and followed for each participant), and the second involved obtaining the tweets in which there were direct mentions between participants, with the intention of counting every mention as a direct relationship. The indirect relations and the mentions were counted using the R Project.

A later phase consisted in building network models with the indirect relations and the mentions. The software program Cytoscape (Smoot, Ono, Ruscheinski, Wang, \& Ideker, 2011) was used to build these network models and to generate the analysis of the network parameters. The software returned a wide variety of parameters and the most meaningful for understanding the data were selected to be included in this paper such as: number of nodes and network diameter, which indicates the network size; average shortest path length; average number of neighbours and clustering coefficient, which indicates the degree of relations established between members; and closeness centrality, which indicates the most popular nodes in a network.

\section{Results}

\section{Results Related to Twitter Data}

Characteristics of the Twitter networks: all participants. The graphical representation of Twitter members' followers and followed people reveals the topology of the global (indirect) network formed by all Twitter users from the nine communities selected in this study (see Figure 1). In Figure 1, the most influential member of the network is highlighted in green, whereas red and yellow nodes 
represent other central participants with less influence. The clustering coefficient of this network is 0.623 , the diameter 5 and the characteristic path length is 2.25, representing thus a small world where every participant is on average only two or three steps away from any other participant in the study.

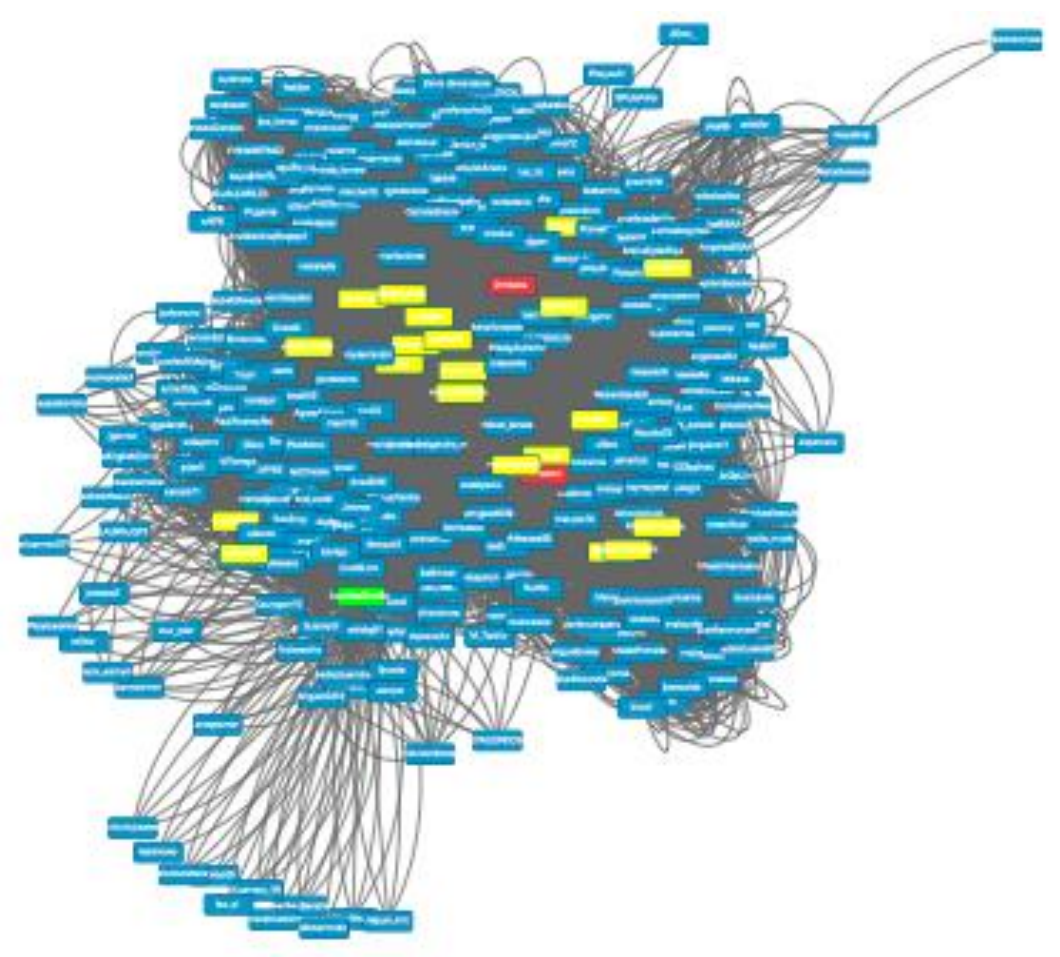

Figure 1. Network representation of participants (nodes) and their connection, either as followers and/or followed members (edges).

Network cluster analysis (Cytoscape, ClusterONE) resulted in 16 different clusters, some of them corresponding to the communities of reference and others corresponding to groups of highly-connected users.

In-degree and out-degree distribution (Figure 2, A and B) indicates the number of connections that every member in the network has. This data evidenced that in the case of the global network of indirect relations, a small number of participants act as hubs, as they are connected to a majority of the members, whereas most participants are connected to less than 80 nodes and the average number of neighbours is 22 (see in Figure 1 the most connected participants highlighted in green and red, and also other central, but less popular participants highlighted in yellow).

The fact that there are several clusters in the network and that twenty-three members act as hubs indicates that the network of all participants corresponds to a community clusters archetype (Smith, Rainie, Shneiderman, \& Himelboim, 2014). That is, members are grouped into several clusters and some of them act as bridges, connecting different clusters. This conversational archetype is characteristic in situations where news or popular topics (trending topics) are commented on. 

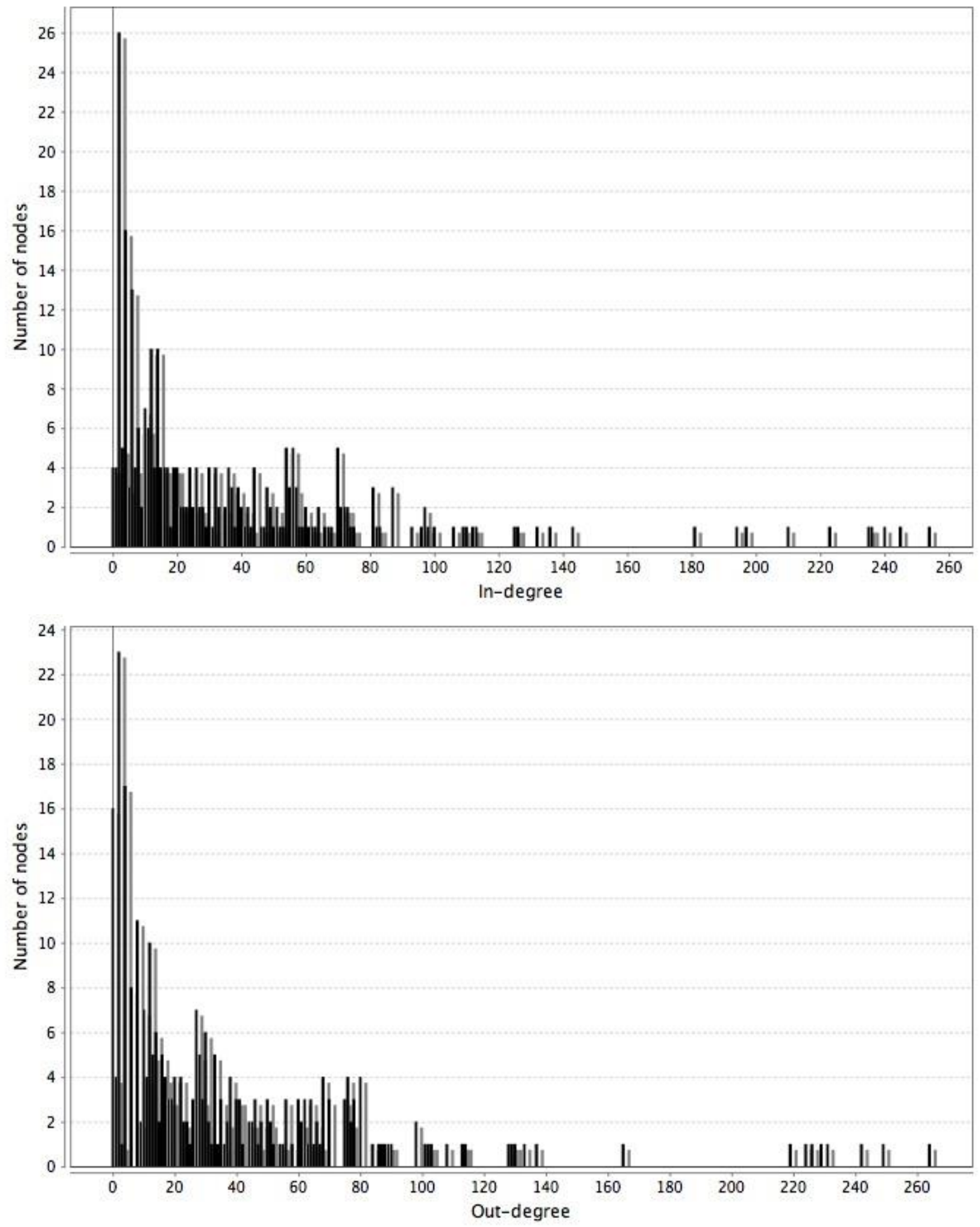

Figure 2. In-degree (A) and out-degree (B) distribution of all the members in the indirect relations network. 


\section{Characteristics of the Conversations in Twitter: All Participants}

Apart from the representation of the followers and followed network members we also analyzed the dynamics of the network in terms of information flow, i.e., conversations, or direct relations established between the participants (see Figure 3). In this case, the clustering coefficient is 0.549 , lower than in the case of the indirect relations; however, it still represents a small world as the diameter is 5 and the characteristic path length is 2.42 .

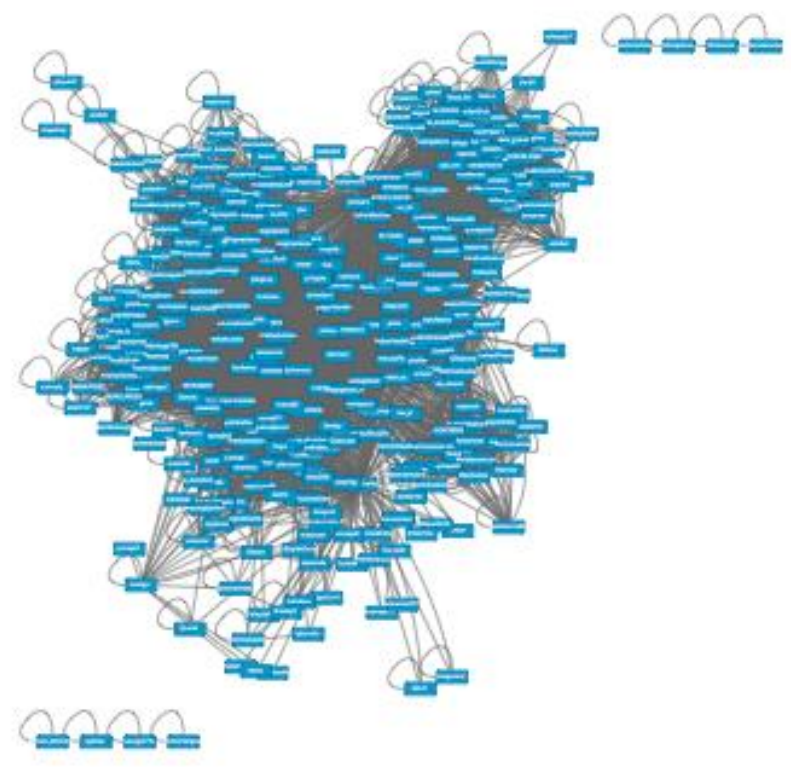

Figure 3. Network representation of participants (nodes) and their connection in mentions (edges).

Within the conversation-based network we identified 39 clusters, with eight of these clusters being bigger than 20 participants. The representation of in-degree distribution (Figure 4A) and out-degree distribution (Figure 4B) evidenced that a single member receives information from a big group of members (receiving more than 170 inputs) and that ten people communicate to a big group of people (around 80 outputs). Around 60 people scarcely receive or send tweets to other members. The conversational archetype in this case also corresponds to a community clusters archetype (Smith et al., 2014) 

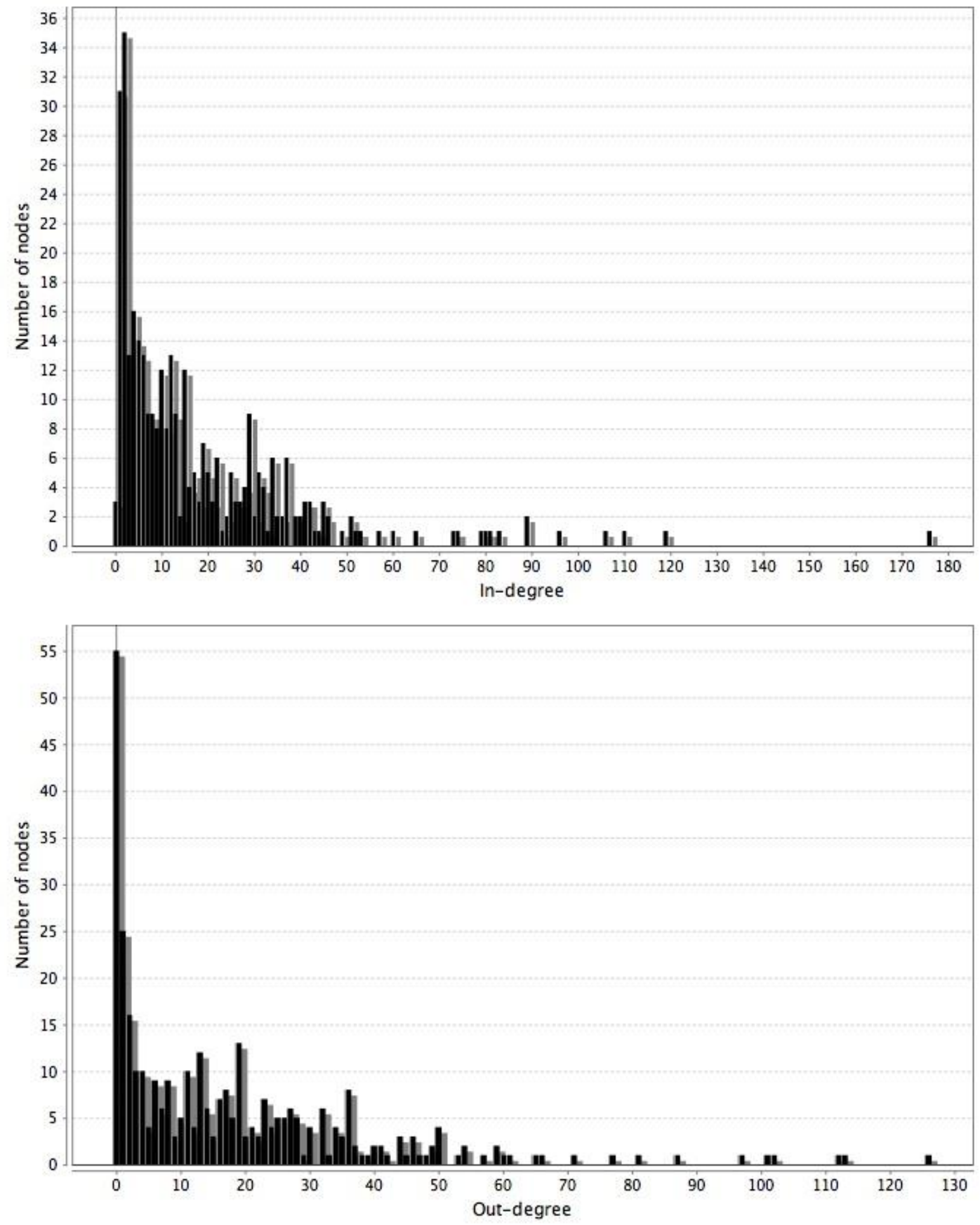

Figure 4. In-degree (A) and out-degree (B) distribution of all the members in the general conversational network. 


\section{Characteristics of the Established Networks in Twitter by Communities}

Communities and relations among their members were also studied separately. The results of these analyses revealed differences between the studied communities (see Table 2). According to the data, there are some communities in which members are highly connected between them, such as the Apps community (see Figure 8), whereas in other cases the connections are only established by part of the members and mainly concentrated around the figure of the leader or moderator. An example of the latter is the case of the Books community in which a group of members is connected among them while many other members remain isolated and are only connected to the leader (see Figure 5).

Table 2

Network Properties in the Case of the Indirect Relations Established Within Each Selected Community

\begin{tabular}{|l|r|r|r|r|r|r|r|r|r|}
\hline $\begin{array}{l}\text { Network } \\
\text { name }\end{array}$ & Books & Apps & Tools & Sound & Music & Film & Art & Words & Robot \\
\hline $\begin{array}{l}\text { Number of } \\
\text { nodes }\end{array}$ & 116 & 40 & 58 & 25 & 26 & 22 & 56 & 46 & 30 \\
\hline $\begin{array}{l}\text { Clustering } \\
\text { Coefficient }\end{array}$ & 0.53 & 0.8136 & 0.7987 & 0.6705 & 0.7963 & 0.8398 & 0.5662 & 0.7361 & 0.7605 \\
\hline $\begin{array}{l}\text { Network } \\
\text { diameter }\end{array}$ & 3 & 3 & 2 & 3 & 2 & 2 & 4 & 2 & 2 \\
\hline $\begin{array}{l}\text { Average } \\
\text { shortest path } \\
\text { length }\end{array}$ & 1.9395 & 1.2654 & 1.3702 & 1.6496 & 1.3169 & 1.3160 & 1.7927 & 1.413 & 1.3978 \\
\hline $\begin{array}{l}\text { Average } \\
\text { number } \\
\text { neighbours }\end{array}$ & 13.9828 & 32.35 & 39.4828 & 9.84 & 18.7692 & 15.1818 & 15.9643 & 29.087 & 17.6667 \\
\hline
\end{tabular}

As we can observe in Table 2, a big community of many participants does not guarantee interchange of information with many members, as happens in Books. The members of this network have an average of 14 connections out of 116 participants in the network. They are mainly connected to the leader of the community and scarcely connected between them, except a part of them who form a cluster inside the network (see Figure 5). In Figure 5, the leader of the network is highlighted in purple, other central participants in blue, some clustered participants in red, and the peripheral participants are shown in yellow and orange. This kind of connection is typical in broadcast networks or support networks (Smith et al., 2014). 


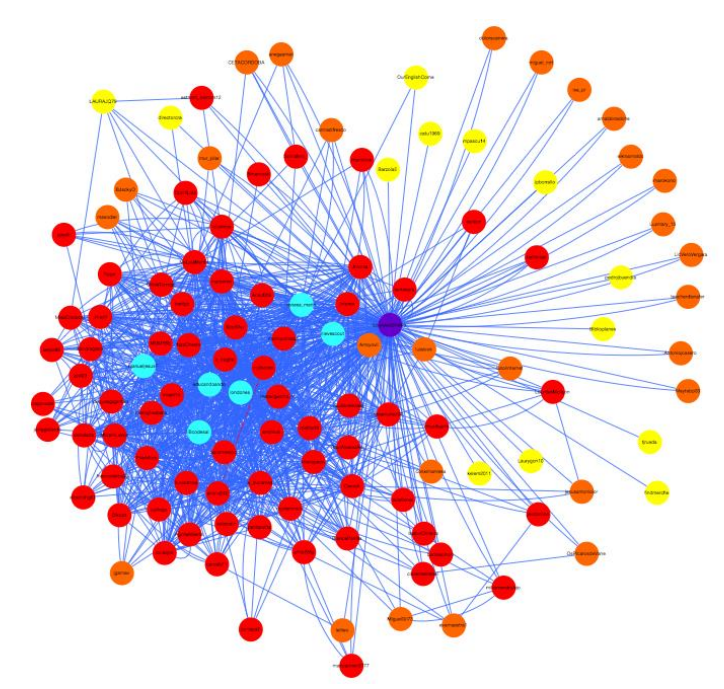

Figure 5. Representation of the Books relations network topology.

In the case of Books, the leader of the community is the person with the most neighbours (see Figure 6) in all the network and is also relevant in in-degree and out-degree centrality (see Figure 7, A and B). In this case, the leader of the community is the person who follows the most members and is more followed in this network and stands as the point of reference for almost all the participants. Other networks with a similar topology to Books are Sound and Art.

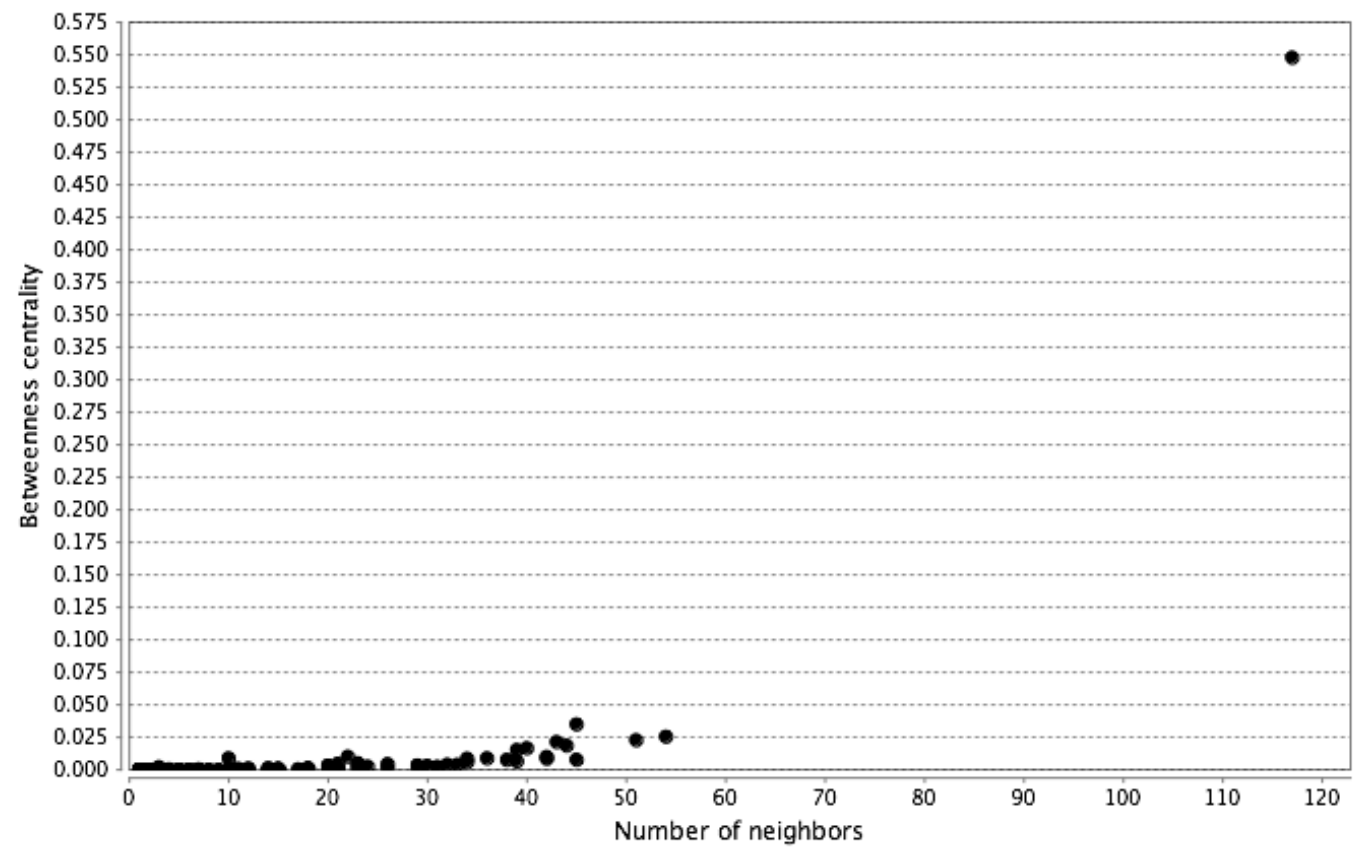

Figure 6. Betweenness centrality of the Books relations network. 

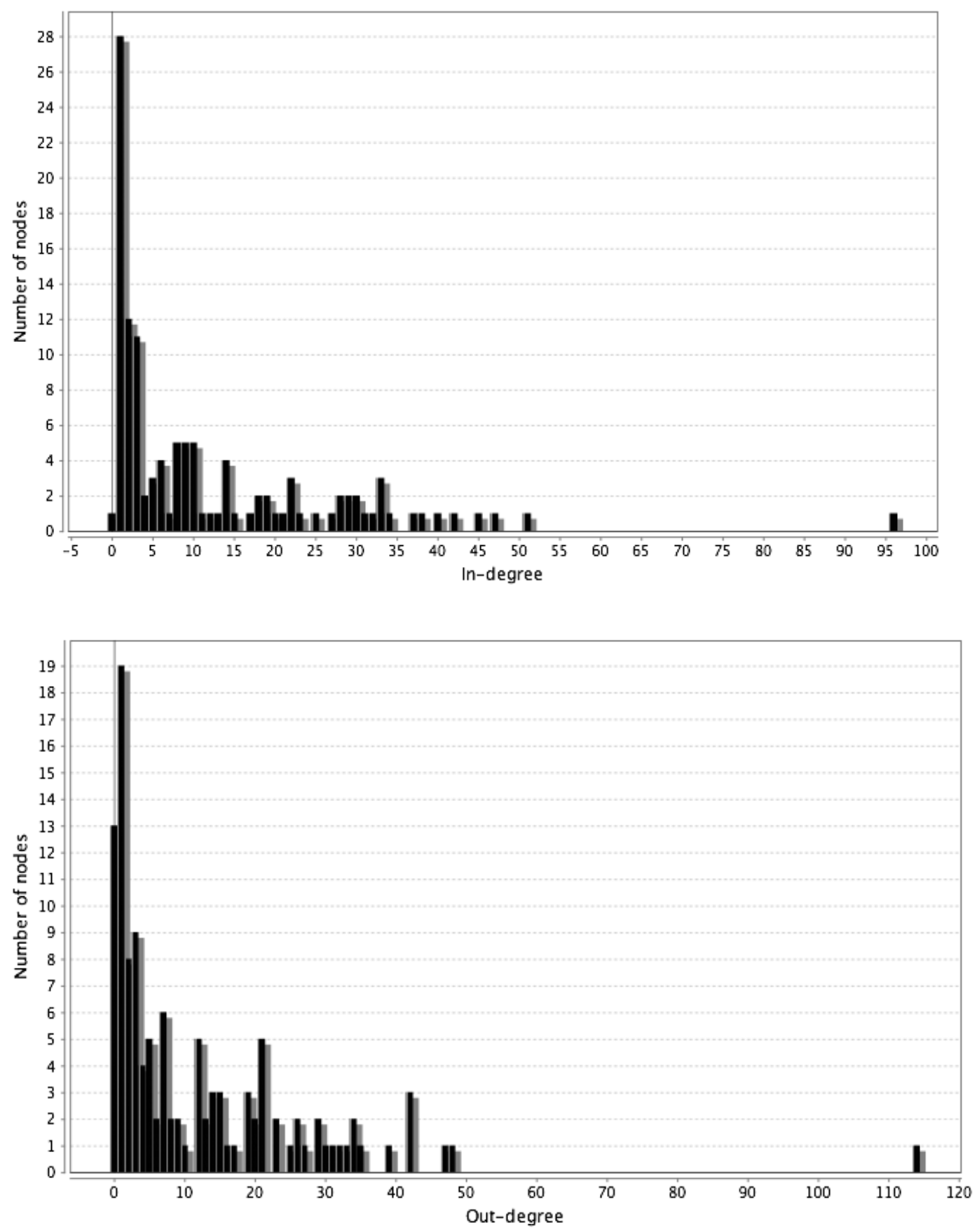

Figure 7. In-degree (A) and out-degree (B) distribution of the members in the Books relations network.

On the other side, small communities with highly-linked members can be a great source of information, as is the case of Apps, whose members have an average number of 32 potential connections out of 40 members. In this case, the community represents a tight crowd as all the members are highly connected between them (see Figure 8). In Figure 8 the two central nodes are highlighted in red and the less connected node in blue. 


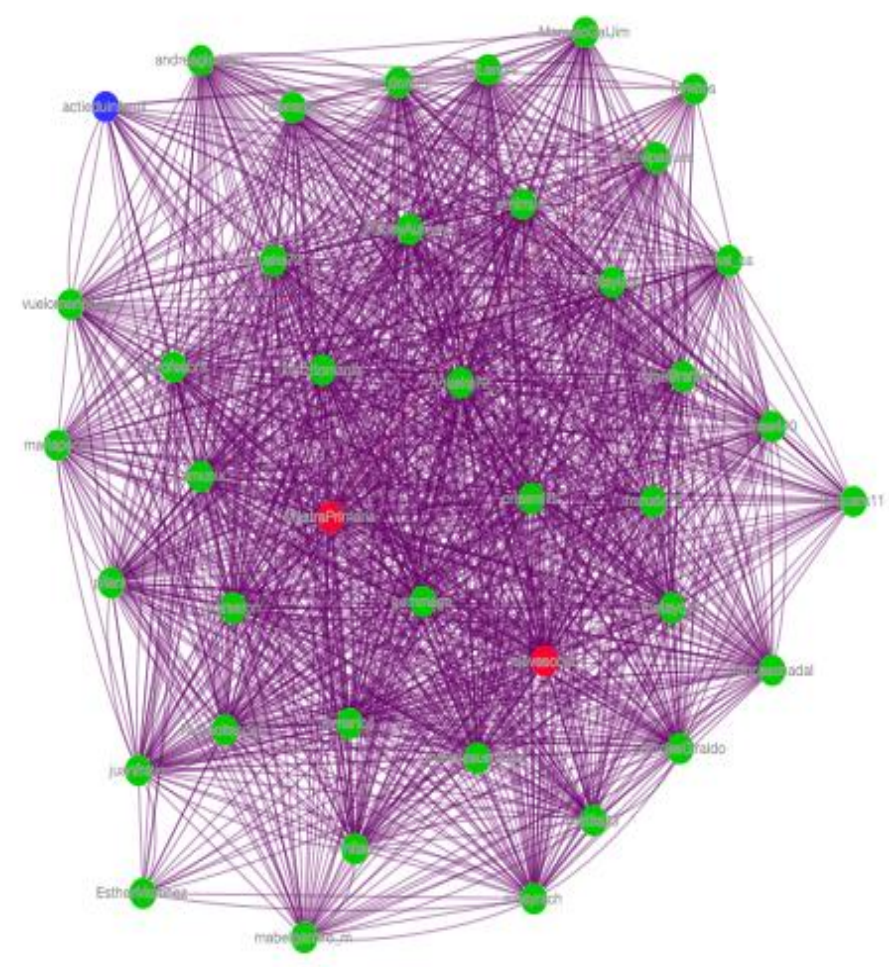

Figure 8. Representation of the Apps relations network topology.

In this network, the leader is one of the two most connected members (see Figure 8, the nodes in red), however the rest of the members are also highly connected with each other, conforming a tight network. The in-degree and out-degree centrality representation confirms that all members are connected at least to six people and most of them are connected to more than 20 people in the community. Other networks similar to Apps are Tools, Music, and Film. Words and Robot also have a leader and many highly connected members; however, the number of peripheral participants is higher than in the previous four networks. 


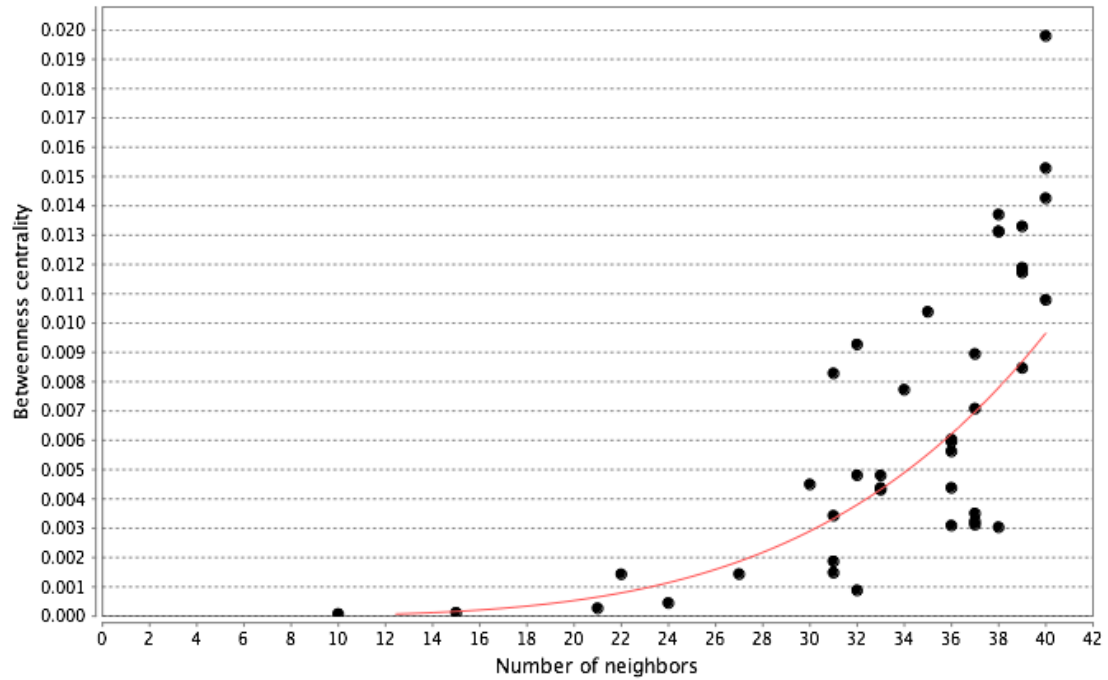

Figure 9. Betweenness centrality of the Apps relations network.

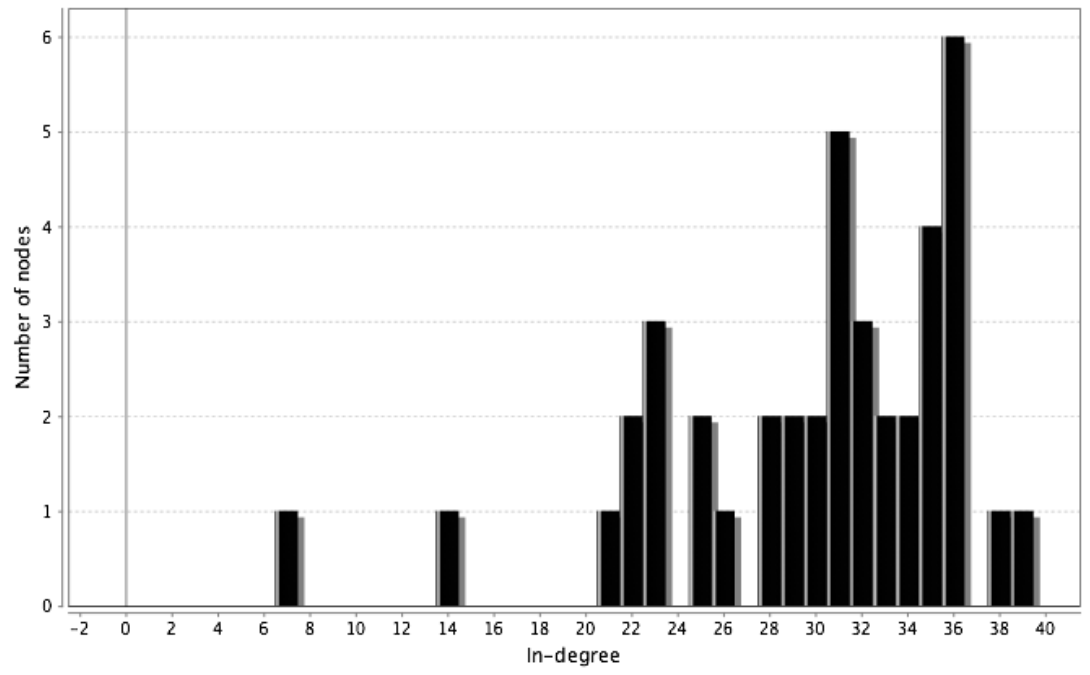




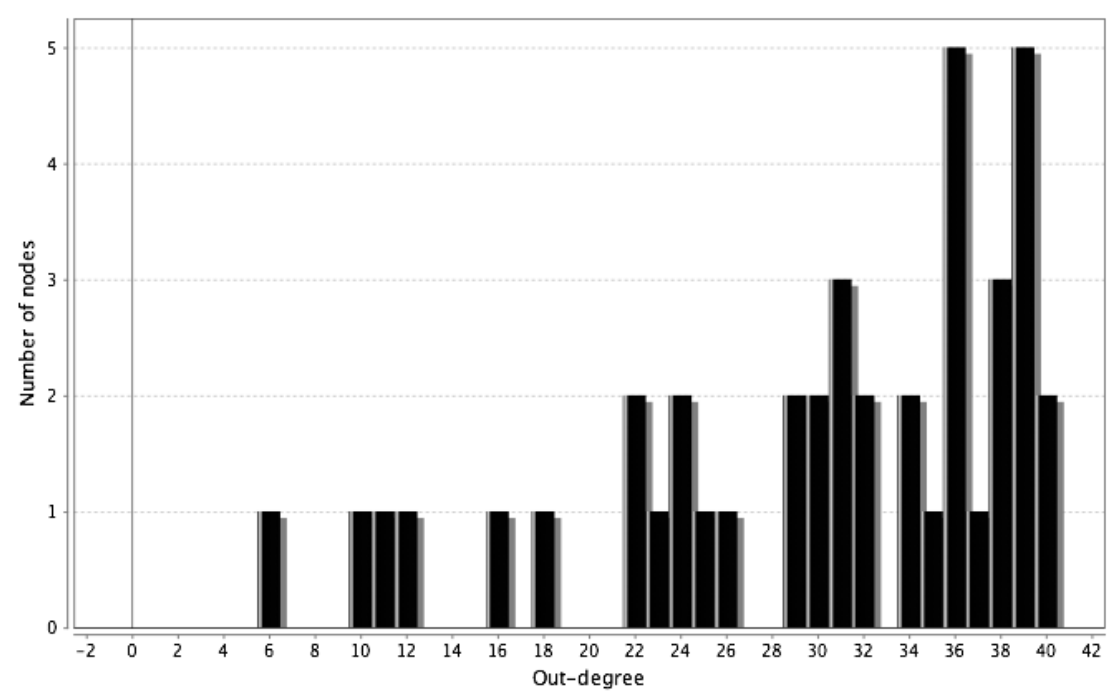

Figure 10. In-degree (A) and out-degree (B) distribution of the members in the Books relations network.

\section{Characteristics of the Conversations Established in Twitter}

The study of the characteristics of the conversations was conducted by extracting the direct mentions in the tweets. The data reveals that the direct interchange of information between members in Twitter is lower than the indirect connection between members. The groups that have higher direct interaction tend to be the smaller groups such as Film and Music, but also include those with a more tightly connected network.

Table 3

Network Properties in the Case of the Direct Relations (Conversations) Established Within Each Selected Community

\begin{tabular}{|l|r|r|r|r|r|r|r|r|r|}
\hline $\begin{array}{l}\text { Network } \\
\text { name }\end{array}$ & Books & Apps & Tools & Sound & Music & Film & Art & Words & Robot \\
\hline $\begin{array}{l}\text { Number of } \\
\text { nodes }\end{array}$ & 114 & 40 & 58 & 25 & 26 & 22 & 53 & 46 & 29 \\
\hline $\begin{array}{l}\text { Clustering } \\
\text { Coefficient }\end{array}$ & 0.4376 & 0.6004 & 0.6383 & 0.6335 & 0.7173 & 0.7236 & 0.5587 & 0.6827 & 0.5829 \\
\hline $\begin{array}{l}\text { Network } \\
\text { diameter }\end{array}$ & 4 & 3 & 3 & 3 & 3 & 2 & 4 & 2 & 3 \\
\hline $\begin{array}{l}\text { Average } \\
\text { shortest path } \\
\text { length }\end{array}$ & 2.1139 & 1.5807 & 1.5541 & 1.6780 & 1.49 & 1.2817 & 1.9103 & 1.4326 & 1.4496 \\
\hline $\begin{array}{l}\text { Average } \\
\text { number } \\
\text { neighbours }\end{array}$ & 11.7193 & 21.8 & 33.1724 & 9.12 & 15 & 11.8182 & 17.2830 & 31.3913 & $\begin{array}{l}13.448 \\
3\end{array}$ \\
\hline
\end{tabular}

If we take a closer look at the Books network we can see that the topology of the conversations is similar to the one formed by indirect relations, with some central nodes and many peripheral participants. In Figure 
11 we can see the leader and center of the network in purple and other central members in red, yellow and light blue.

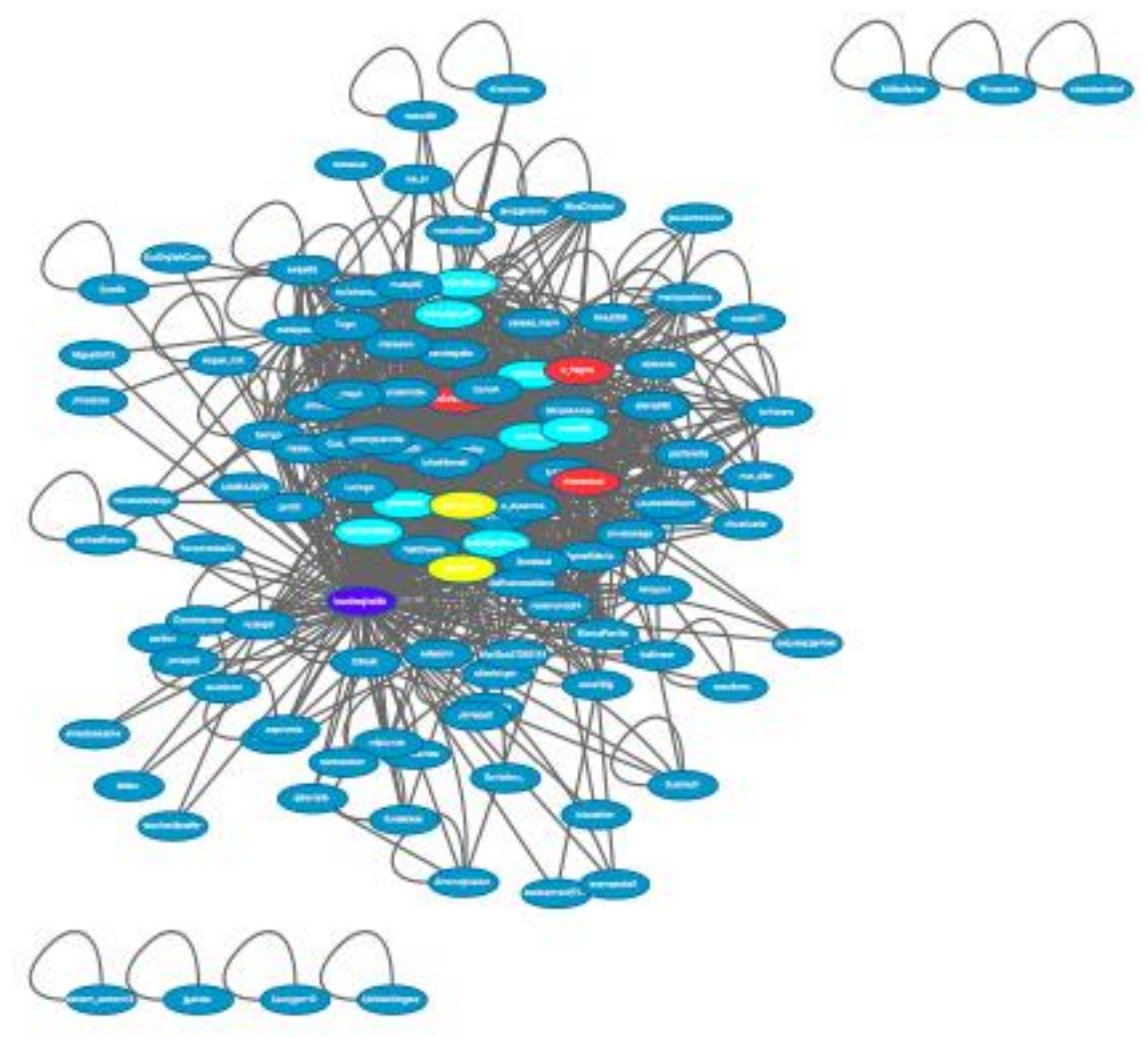

Figure 11. Representation of the Books conversational network topology.

If we analyze the in-degree and out-degree distributions we can see that there is a central node, the leader, who sends almost all the information that circulates in the network. The other members receive some information through mentions in tweets, but their level of exchange in general is poor. This conversational pattern is similar to the Art and Sound networks. 


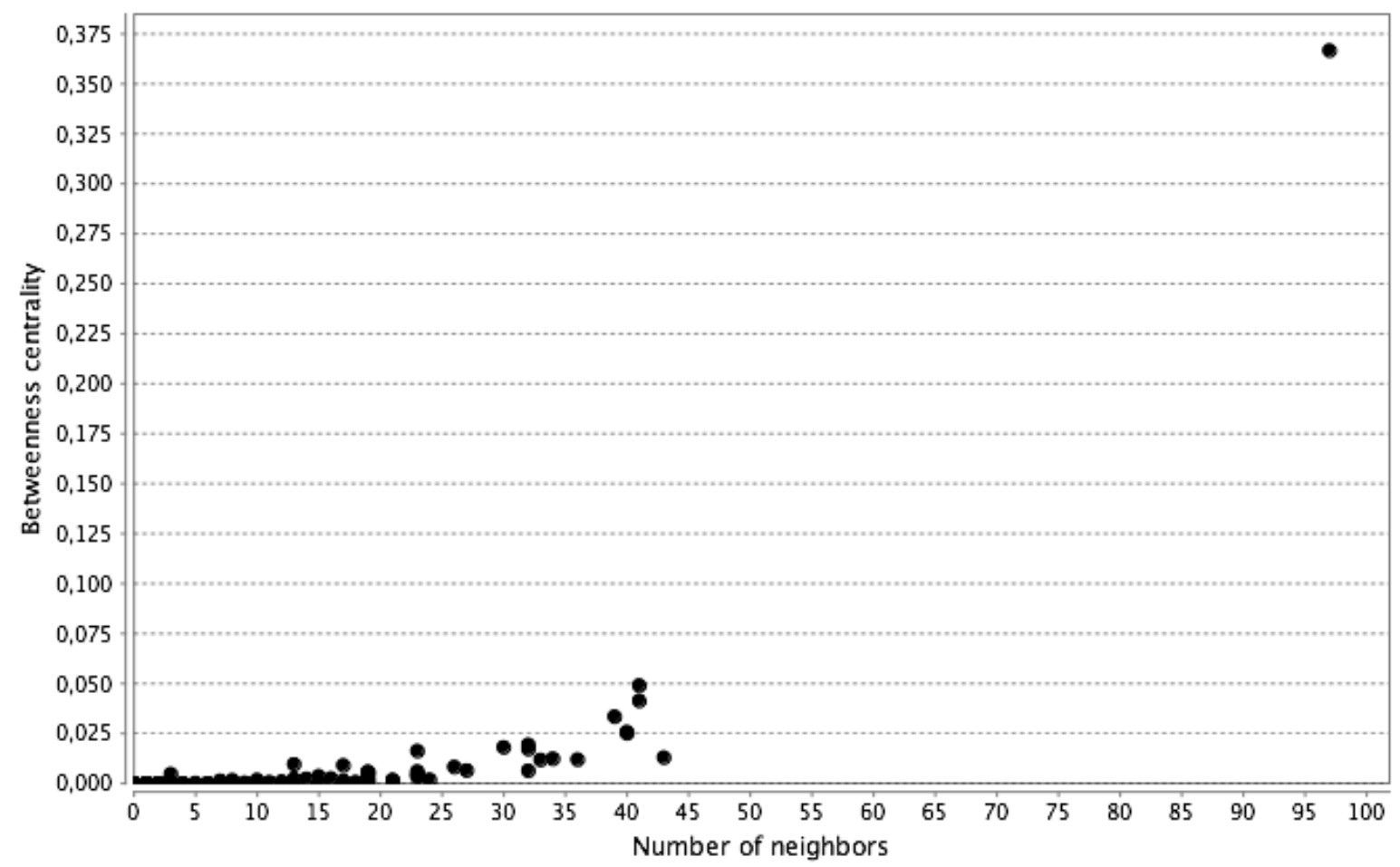

Figure 12. Betweenness centrality of the Books conversational network.

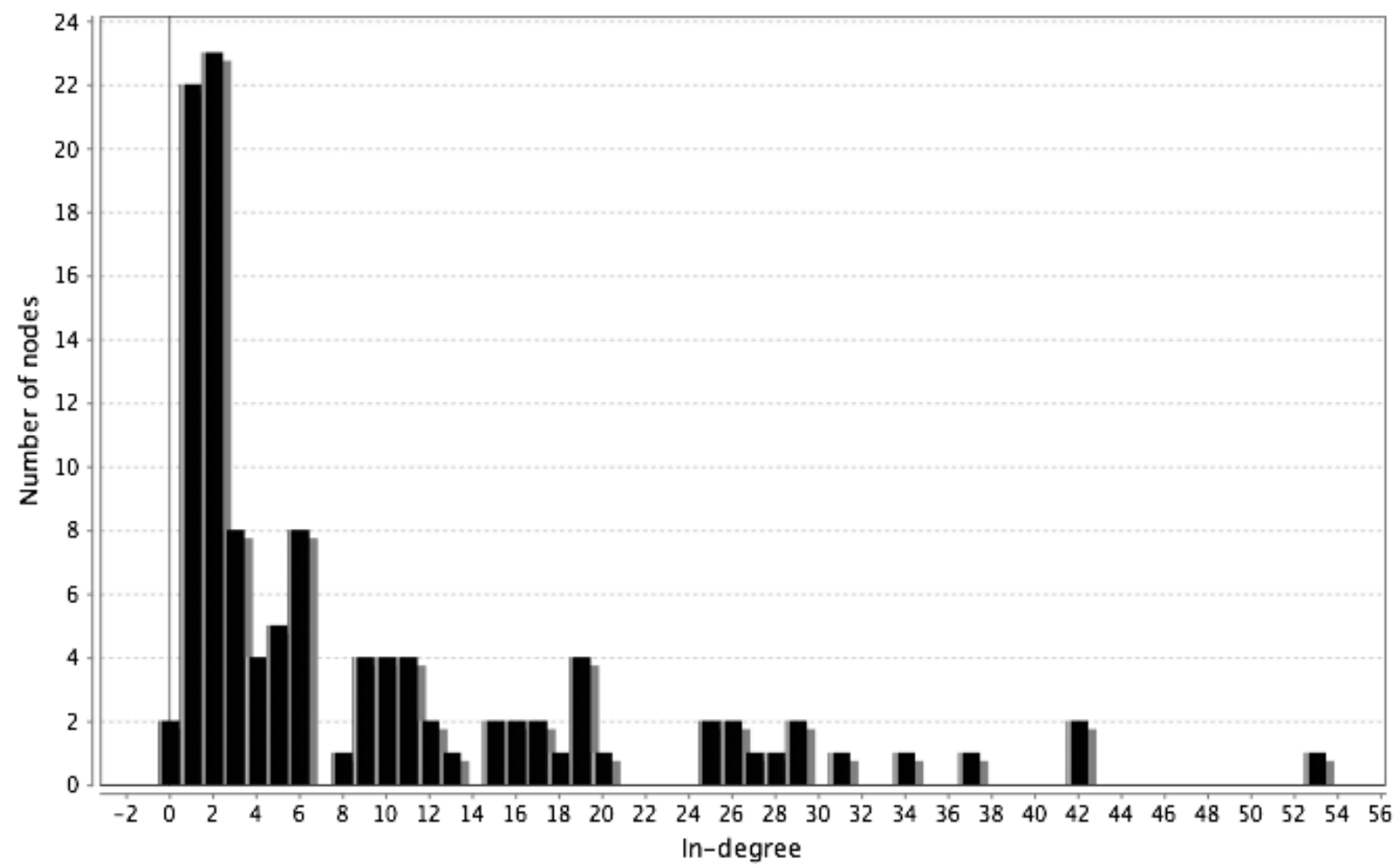




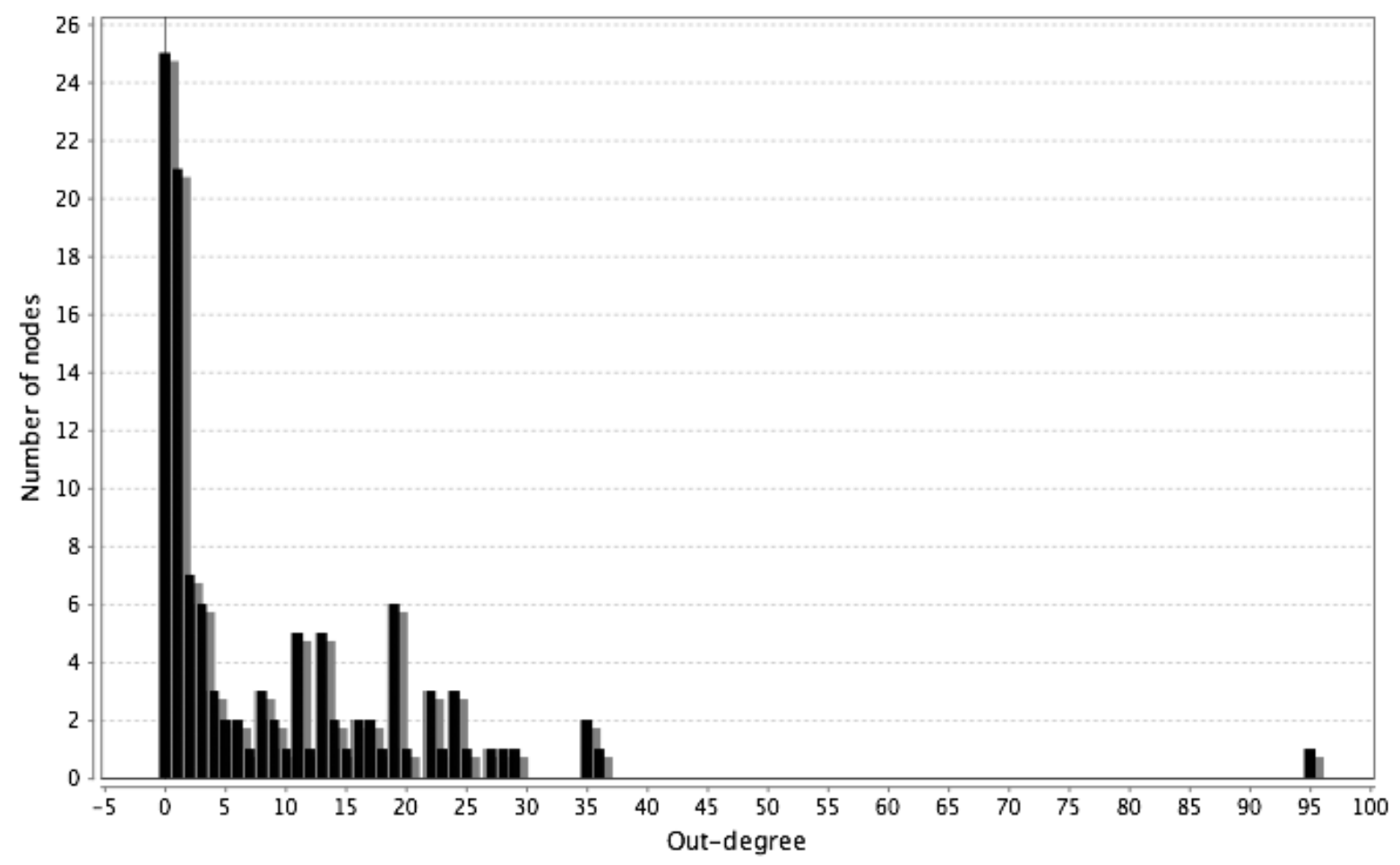

Figure 13. In-degree (A) and out-degree (B) distribution of all the members in the Books conversational network.

In the case of the conversations in the Apps network, the resultant figure is similar to the one for indirect connections; all the members communicate with other members, and some of them have a higher rate of communication (see Figure 14). 


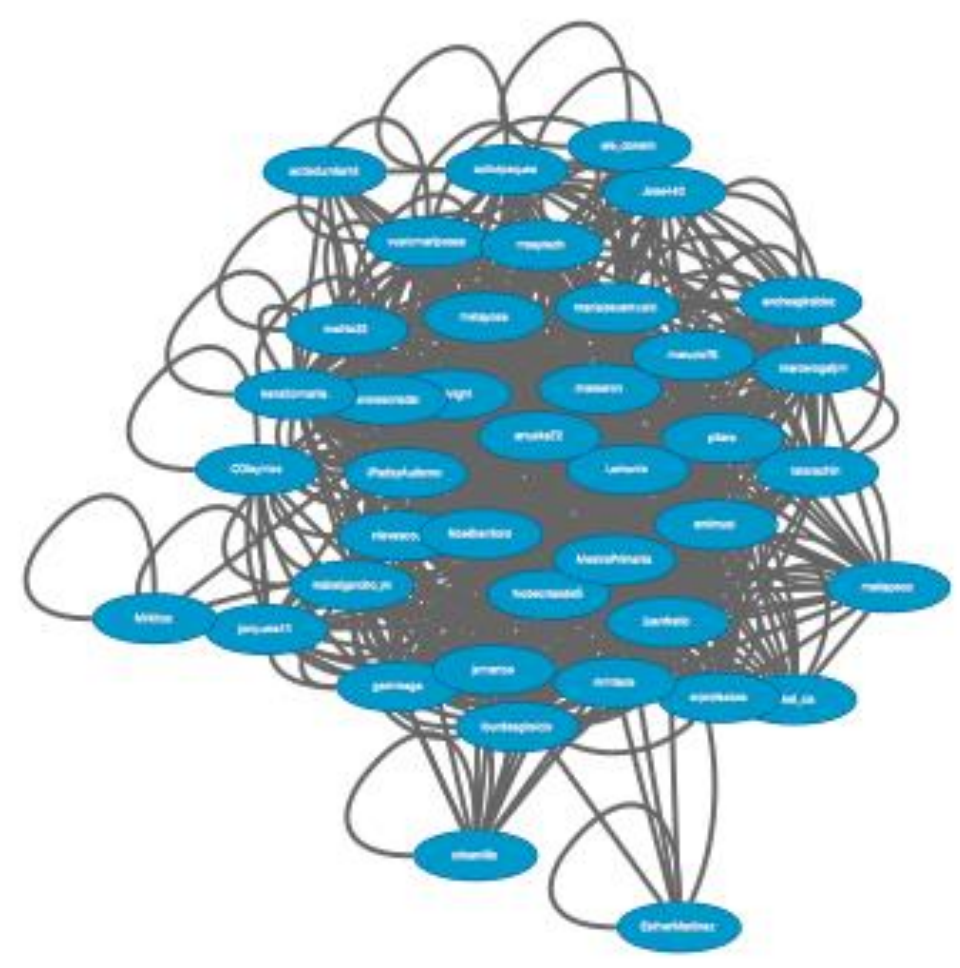

Figure 14. Representation of the Apps conversational network topology.

The data shows that members have similar rates of centrality degree, so the central position is not clearly attributed to a leader, as several members play this role, generating a distributed leadership. In-degree and out-degree distributions confirm that almost all the members exchange some information. We can also find this conversational pattern in the networks Tools, Music, and Film. In the case of the Words and Robot networks, there are many members who do not participate in the conversations. 
Properties of Teacher Networks in Twitter: Are They Related to Community-Based Peer Production? Macià and Garcia

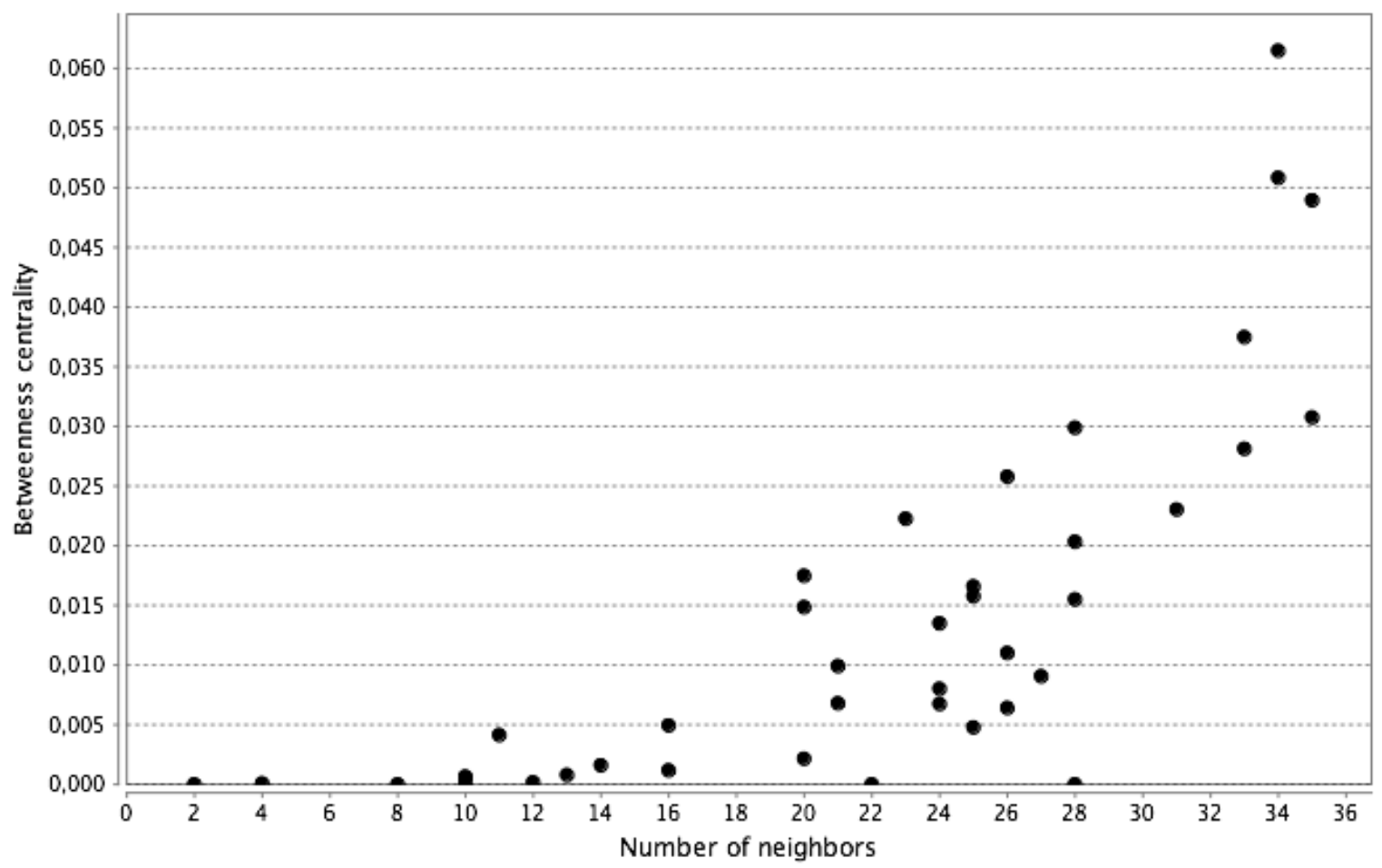

Figure 15. Betweenness centrality of the Apps conversational network.

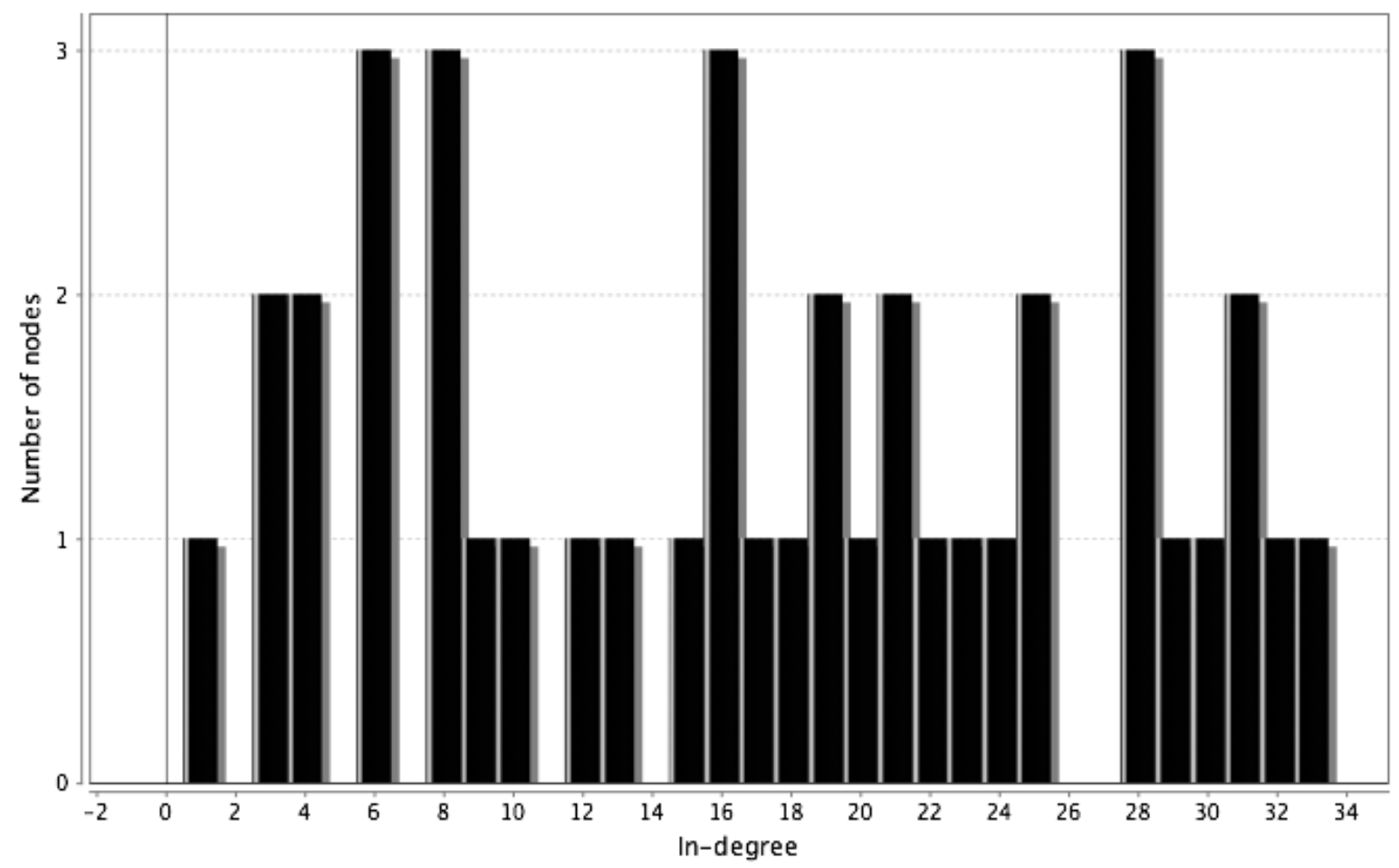




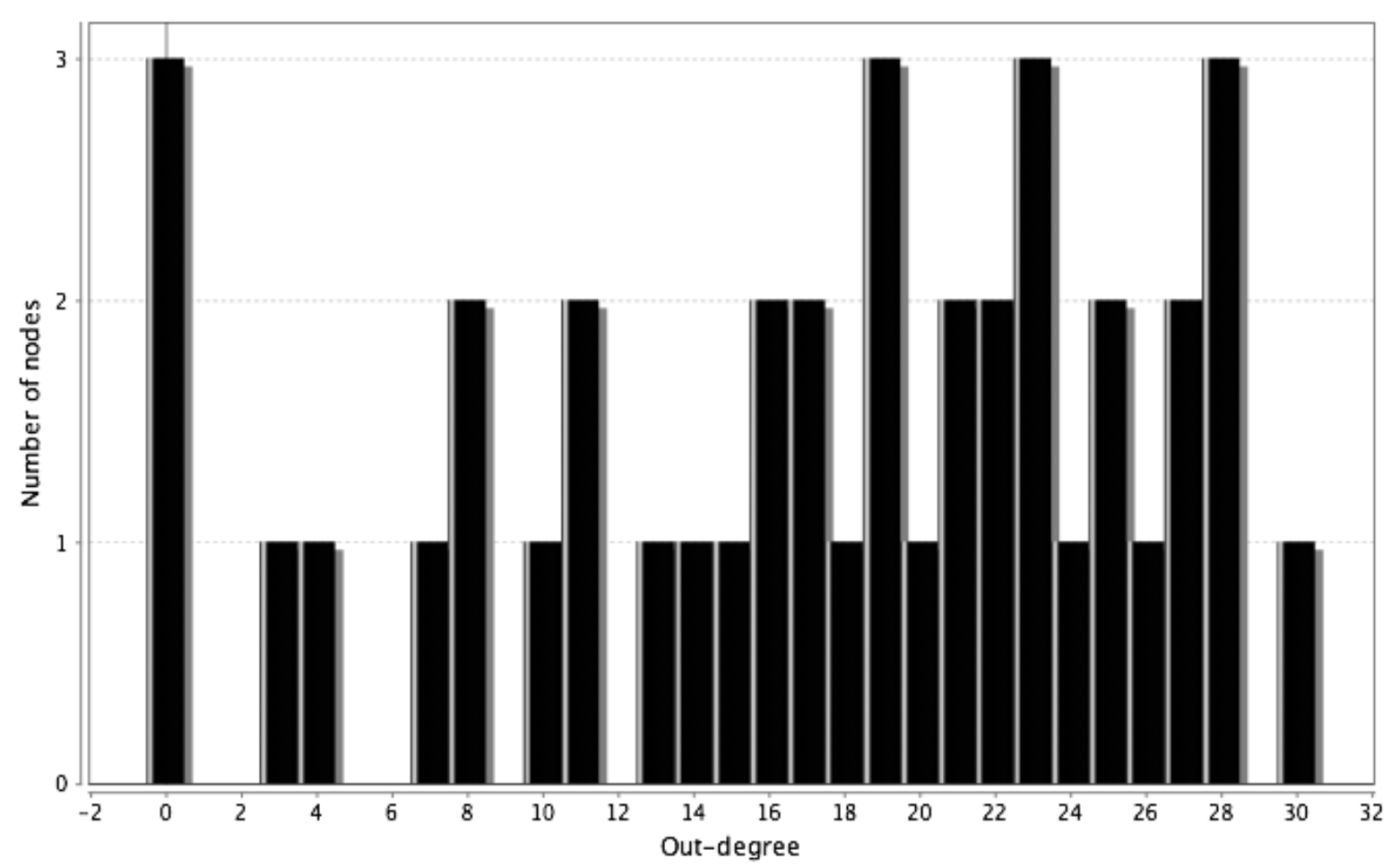

Figure 16. In-degree (A) and out-degree (B) distribution of all the members in the Apps conversational network.

\section{Members Adopting a Bridging Role}

According to Granovetter (1983, 1973), weak ties between participants encourage the appearance of bridging roles, which means that participants are present in several groups of discussion with a lowintensity presence. These bridging roles are crucial in disseminating information across the network. In this study we considered as bridges those teachers participating in more than one studied community. In total, 55 teachers formed part of two or more communities, thus representing up to $16.5 \%$ of the total participants. The majority of these bridges belonged to two communities, although 17 of them belonged to three or more communities.

Table 4

Number of Teachers Acting as Bridges

\begin{tabular}{|l|l|}
\hline $\begin{array}{l}\text { Number of communities } \\
\text { joined }\end{array}$ & $\begin{array}{l}\text { Number of teachers acting as } \\
\text { bridges }\end{array}$ \\
\hline Belong to 6 communities & 1 \\
\hline Belong to 5 communities & 4 \\
\hline Belong to 4 communities & 5 \\
\hline
\end{tabular}




\begin{tabular}{|l|l|}
\hline Belong to 3 communities & 7 \\
\hline Belong to 2 communities & 38 \\
\hline
\end{tabular}

Interestingly, the analysis of the profiles of the teachers participating in more than three communities yielded profiles corresponding to experienced Twitter users, with at least 1,00o tweets publicly posted and with more than 400 followers each.

Table 5

Profile of Members Belonging to Three or More Communities

\begin{tabular}{|c|c|c|c|c|c|c|}
\hline Member & $\begin{array}{l}\text { Number of } \\
\text { communities }\end{array}$ & Followers & Followed & $\begin{array}{l}\text { Number of } \\
\text { tweets }\end{array}$ & $\begin{array}{l}\text { Closeness } \\
\text { centrality } \\
\text { relations }\end{array}$ & $\begin{array}{l}\text { Closeness } \\
\text { centrality } \\
\text { tweets }\end{array}$ \\
\hline$@ \mathrm{~A}$ & 6 & 1630 & 955 & 25395 & 0.6043 & 0.5667 \\
\hline$@ \mathrm{~B}$ & 5 & 1444 & 1183 & 13898 & 0.6191 & 0.5698 \\
\hline$@ \mathrm{C}$ & 5 & 2043 & 2128 & 13715 & 0.6303 & 0.5097 \\
\hline$@ \mathrm{D}$ & 5 & 2595 & 1820 & 9762 & 0.6164 & 0.5678 \\
\hline$@ \mathrm{E}$ & 5 & 2637 & 1023 & 6600 & 0.5965 & 0.5667 \\
\hline$@ \mathrm{~F}$ & 4 & 4465 & 4877 & 53265 & 0.6205 & 0.4875 \\
\hline$@ \mathrm{G}$ & 4 & 3590 & 767 & 6868 & 0.4579 & 0.4764 \\
\hline$@ \mathrm{H}$ & 4 & 1210 & 506 & 2852 & 0.5638 & 0.5413 \\
\hline$@ \mathrm{I}$ & 4 & 2084 & 2112 & 20104 & 0.5593 & 0.4786 \\
\hline$@ \mathbf{J}$ & 4 & 1017 & 1559 & 4064 & 0.6233 & 0.5647 \\
\hline$@ \mathrm{~K}$ & 3 & 4548 & 3437 & 18787 & 0.5045 & 0.4283 \\
\hline$@ \mathrm{~L}$ & 3 & 1472 & 1504 & 12871 & 0.5009 & 0.5105 \\
\hline$@ \mathrm{M}$ & 3 & 778 & 305 & 1837 & 0.5472 & 0.5139 \\
\hline$@ \mathrm{~N}$ & 3 & 3581 & 2185 & 12012 & 0.5673 & 0.4875 \\
\hline$@ \mathrm{O}$ & 3 & 1721 & 621 & 4968 & 0.5429 & 0.5015 \\
\hline$@ \mathrm{P}$ & 3 & 1010 & 979 & 8184 & 0.5356 & 0.4651 \\
\hline$@ \mathbf{Q}$ & 3 & 421 & 434 & 2960 & 0.5196 & 0.4631 \\
\hline
\end{tabular}


Table 6

Average Profile of all the Members Classified According to the Number of Communities they Belong to

\begin{tabular}{|l|l|l|l|l|l|}
\hline $\begin{array}{l}\text { Number of } \\
\text { communities }\end{array}$ & Followers & Followed & $\begin{array}{l}\text { Number of } \\
\text { tweets }\end{array}$ & $\begin{array}{l}\text { Closeness } \\
\text { centrality } \\
\text { relations }\end{array}$ & $\begin{array}{l}\text { Closeness } \\
\text { centrality } \\
\text { tweets }\end{array}$ \\
\hline 6 & 1630 & 955 & 25395 & 0.6043 & 0.5667 \\
\hline 5 & 2179.7 & 1539 & 10994 & 0.6156 & 0.5535 \\
\hline 4 & 2473.2 & 1964 & 17431 & 0.565 & 0.5097 \\
\hline 3 & 1933 & 1352 & 8803 & 0.5311 & 0.4814 \\
\hline 2 & 1976 & 1522 & 11124 & 0.5093 & 0.4646 \\
\hline 1 & 1301 & 1033 & 7147 & 0.3589 & 0.3214 \\
\hline Average & & & & & \\
\hline 1.26 & 1431 & 1122 & 7951 & 0.4335 & 0.3269 \\
\hline
\end{tabular}

\section{Results Related to Data on Communities' Websites}

Peer production on the communities' websites. All the studied communities had a website with educational content collaboratively published by the members of the community. The analysis performed on these websites consisted of studying their production in terms of published posts or pages (see Table 7) and also the possibility of participating in the website by making lightweight contributions (see Table 8), for example, incorporating instructions on how to contribute content for the website. As the results show, networks with a low clustering coefficient tend to have a low rate of publications per month, e.g., the Music and Art networks. This situation could be explained by the fact that this group of teachers offered the possibility of participating in a lightweight mode, so many of the teachers who contributed were possibly not really engaged in the community.

Surprisingly, the Books network, which had a low clustering coefficient, had a high rate of publication, which could be explained by the strong leadership and the important time investment required to participate in this community, focused on developing digital books.

The Books, Film, and Robot communities ended their production during the same school year they were created. This fact seems unrelated to the tightness of the network or the leadership, considering the different characteristics of these communities. The Words community is not a dense network but it did yield extensive production, which could be also explained by its strong leadership. 
Table 7

Production in the Communities' Websites in Terms of Publications Created Per Month

\begin{tabular}{|c|c|c|c|c|c|c|c|c|c|}
\hline Project & Books & Apps & Tools & Sound & Music & Film & Art & Words & Robot \\
\hline $\begin{array}{l}\text { Time (months } \\
\text { until January } \\
\text { 2016) }\end{array}$ & 10 & 43 & 50 & 36 & 53 & 11 & 30 & 40 & 12 \\
\hline $\begin{array}{l}\text { Number of } \\
\text { posts/pages }\end{array}$ & $\begin{array}{c}140 \text { book } \\
\text { pages }\end{array}$ & $\begin{array}{c}364 \\
\text { posts }\end{array}$ & $\begin{array}{c}682 \\
\text { posts }\end{array}$ & $\begin{array}{c}569 \\
\text { posts }\end{array}$ & $\begin{array}{c}359 \\
\text { posts }\end{array}$ & $\begin{array}{c}78 \\
\text { posts }\end{array}$ & $\begin{array}{c}139 \\
\text { posts }\end{array}$ & $\begin{array}{c}768 \\
\text { posts }\end{array}$ & $\begin{array}{c}49 \\
\text { pages }\end{array}$ \\
\hline $\begin{array}{l}\text { Post/page per } \\
\text { month }\end{array}$ & 14 & 8.5 & 13.6 & 15.8 & 6.8 & 7.1 & 4.6 & 19.2 & 4.1 \\
\hline $\begin{array}{l}\text { Number of } \\
\text { publishers } \\
\text { (January 2016) }\end{array}$ & 179 & 55 & 72 & 37 & 48 & 33 & 40 & 135 & 43 \\
\hline
\end{tabular}

Table 8

Existence of Instructions to Sustain Lightweight Production on the Website

\begin{tabular}{|c|c|c|c|c|c|c|c|c|c|}
\hline Project & Book & Apps & Tools & Sound & Music & Film & Art & Words & Robot \\
\hline $\begin{array}{l}\text { Instructions for } \\
\text { participating }\end{array}$ & No & No & No & Yes & Yes & No & Yes & Yes & No \\
\hline
\end{tabular}

\section{Discussion}

Below we discuss the results in relation to the research questions raised.

\section{RQ1: What are the properties of teachers' networks in social networking sites and how is information shared within them?}

The indirect relations and the conversational teachers' networks in Twitter both represent a community clusters archetype (Smith et al., 2014). This archetype consists of several groups of members who are connected in clusters, some bridges connecting the diverse clusters and some other members participating from a peripheral position. According to Smith et al. (2014), networks distributed as community clusters represent groups who gather around a topic or a person who acts as a hub. In the case of the communities included in the sample, the topic of interest could correspond to the community domain. Although the network is organized into small groups, the teachers who are connected with several groups (i.e., acting as bridges) bring the whole network a certain degree of tightness, so the information can spread easily. Professional networks tend to adopt a tight crowd archetype, but in the studied networks teachers created clustered networks. This phenomenon could occur when teachers gather according to their interests. Within a networked context, people tend to connect to other members

${ }^{1}$ Highlighted cells indicate that communities are no longer active. Books ended its activity in July 2014, Film in August 2014, and Robot in November 2014. 
with similar interests, and this phenomenon is known as homophily (McPherson, Smith-Lovin, \& Cook, 2001; Tajfel, 2010).

The indirect relations networks are tighter than the conversational networks. This phenomenon could be explained by the fact that following or being followed requires a single action, which only has to be done once, whereas tweeting (mentioning someone in a tweet) is a more complex action, which requires more than a single mouse click. However, it does not necessarily indicate a higher degree of cohesion in terms of sharing information and resources and knowledge building among its members. It is probably also related to the nature of communication in Twitter (and other social networks), which is more distributed among diverse people and not as focused on particular interlocutors.

\section{RQ2: Do teachers' networks have particular properties and characteristics compared to general population Twitter networks?}

According to Kwak, Lee, Park, and Moon (2010), Twitter can be considered more a source of information rather than a social networking site, as the level of reciprocity is low (i.e., only $22.2 \%$ of users have reciprocal relationships). In the case of teachers' networks, we could say that the relations tend to be reciprocal as many of them have a similar number of followers and followed people (the average of the sample is 1431 followers and 1122 followed people).

Regarding the degree of separation in general Twitter networks, the average path length is 4.12, and $70.5 \%$ of the node pairs are connected with a path length of 4 or shorter, while $97.6 \%$ of the node pairs have a path length of 6 or shorter (Kwak et al., 2010). In the studied networks, the average path length is 2.25 in the case of indirect relations, and 2.42 in the case of conversations. Thus, the studied teachers' networks are much tighter than the general network established in Twitter.

Kwak et al. (2010) also found that Twitter users with less than 1000 followers and reciprocal relations tended to be geographically located close together and have a similar number of followers. These two characteristics also correspond to the teachers' networks, proving that homophily applies to this type of networks (McPherson, Smith-Lovin, \& Cook, 2001; Tajfel, 2010).

The analysis of teachers' relations and conversations in Twitter shows that the network is tighter than the general networks established in Twitter, the relationships are reciprocal (contrary to the general case) and path length is shorter than in the general network. Accordingly, in the case of teachers, they use Twitter as a social networking site (rather than a source of information). In this sense it is important to note that these networks are virtual communities of reference in which these teachers participate.

\section{RQ3: What kind of Twitter profile do teachers who participate in more than one community have (i.e., who act as bridges)?}

All teachers acting as bridges are experienced users of Twitter, as the average number of followers, followed people, and tweets is higher in all cases than the average of people participating in only one network or the average of the sample. These teachers also have higher degrees of centrality in indirect relations and in conversational networks, so the fact of belonging to more than one community expands the number of relations they establish, providing them with more information. These findings ratify the 
results of previous studies which demonstrated the prominent role of bridging people in sustaining higher rates of communication (Schlager et al., 2009) or community involvement and social engagement (Kavanaugh, Reese, Carroll, \& Rosson, 2005). According to Kavanaugh et al. (2005), communities that have people acting as bridges, as well as strong ties within groups, can better collaborate and their production is more effective. Presumably, teachers participating in several groups have more learning and professional development opportunities, but it is also necessary for these teachers to have tight relationships with their colleagues to improve collective action in schools.

\section{RQ4: Is it possible to identify a relation between the studied networks and peer production patterns in the communities of reference?}

Our results seem to indicate that two network factors are related to peer production in the website: the tightness of the network and strong leadership. We hold that the fact of adopting one of the two models of participation, lightweight or heavyweight, has an effect on the Twitter network generated (Haythornthwaite, 2009). When participants can collaborate in a discrete action, they do not need to exchange information with other members in the network. This kind of collaboration can weaken the networks and fosters peripheral collaboration. However, a heavyweight peer production model does not guarantee interaction between members. This is the case of Books, a community in which the leader of the network provides all the necessary elements to sustain cooperation to create digital books. In this network, all members are strongly connected to the leader who settles the rules and coordinates the collaborative project. The members of the Books network interact in Twitter, but their interchange is not necessary to sustain the common goal of the community, as each contribution, although it requires a longterm commitment, can be developed individually.

The role of the leader in a network can be assumed by one person or be distributed among the participants. In both cases it is an important role, as it can encourage participants to engage and share knowledge, especially at the beginning when some participants may not dare to post messages, and at later stages, when participation may decrease. Other strategies to foster participation include incorporating new members and alternating the leading roles to avoid burn out (Wenger, McDermott, \& Snyder, 2002).

\section{Conclusion}

The analysis of the teachers' networks established in Twitter indicates that this collective of professionals constitute a clustered network in the case of indirect relations, and also, in the case of sustained conversations. Hence, interaction is limited to a group of people, which can vary in number of participants. Some teachers act as bridges, disseminating information between the groups. These teachers have a more centric role in the networks and are also slightly more active in Twitter than other colleagues. Thus, a good recommendation to foster professional development is to try to be connected to different groups of teachers in order to receive more information and increase learning opportunities.

The production pattern of the studied communities in some cases is lightweight and in others is heavyweight peer production. To develop the second model, which requires a long-term commitment, it is 
necessary to have a tight network of participants and also a strong leadership, which in some cases could even replace tight relations in a network. This finding demonstrates that the role of the moderator or leader in a network is important for fostering participation, similarly to what occurs in virtual communities. Thus, to foster online professional development for teachers it would be interesting to plan collaborative projects managed by skilled teachers with a strong leader profile. Grassroots informal collaboration can be productive only when the group forms a tight network and every member is committed to a common goal, adopting the attributes of a community.

This research has two main limitations: (a) the studied sample is small and made up of already formed groups of teachers and (b) data was collected only once. Thus, it would be interesting to analyze the same parameters (clustering coefficient, network diameter, betweenness centrality, etc.) in a bigger sample formed of teachers not participating in communities in order to explore the kind of participation by teachers who are not committed to any group. It would also be interesting to compare data collected at several different points to examine how the relationship between members evolves over time.

Future research lines in this study would include a qualitative analysis of communication and community dynamics in order to fully understand the interactions between community-based and network-based aspects in the same group of teachers. Regarding the bridging roles, it would be interesting to analyze how this profile is acquired (Do teachers develop this profile in a long process of gradually increasing participation in Twitter, or have they participated in several groups since the beginning?) and these teachers' roles in their schools (Do they act as bridges between colleagues by promoting teacher interchange?). Another critical aspect that remains unexplored is how teachers' participation in online communities and networks is reflected in their school practices.

\section{References}

Carpenter, J. P., \& Krutka, D. G. (2014). How and why educators use Twitter: A survey of the field. Journal of Research on Technology in Education, 46(4), 414-434.

Carpenter, J. P., \& Krutka, D. G. (2015). Engagement through microblogging: Educator professional development via Twitter. Professional Development in Education, 41(4), 707-728.

Coutinho, C. P., \& Lisbôa, E. S. (2013). Social networks as spaces for informal teacher professional development: Challenges and opportunities. International Journal of Web Based Communities, 9(2), 199-211.

Davis, K. (2015). Teachers' perceptions of Twitter for professional development. Disability and Rehabilitation, 37(17), 1551-1558. 
Dron, J., \& Anderson, T. (2009). How the crowd can teach. In Handbook of research on social software and developing community ontologies (S. Hatzipanagos \& S. Warburton, pp. 1-17). Hershey, PA: IGI Global Information Science.

Forte, A., Humphreys, M., \& Park, T. H. (2012). Grassroots professional development: How teachers use Twitter. In ICWSM. Retrieved from http://www.aaai.org/ocs/index.php/ICWSM/ICWSM12/paper/viewFile/4585\%26lt\%3B/4973

Gentleman, R., Ihaka, R., Bates, D., \& others. (1997). The R project for statistical computing. [Computer software]. Retrieved January 16, 2014 from http://www.R-Project.Org

Gentry, J. (2013). Package 'twitteR.' [Twitter web API interface]. Retrieved January 22, 2014 from https://cran.r-project.org/web/packages/twitteR/twitteR.pdf

Granovetter, M. (1983). The strength of weak ties: A network theory revisited. Sociological Theory, 1(1), 201-233.

Granovetter, M. S. (1973). The strength of weak ties. American Journal of Sociology, 1360-1380.

Haythornthwaite, C. (2009). Crowds and communities: Light and heavyweight models of peer production. In System Sciences, 2009. HICSS'o9. 42nd Hawaii International Conference on (pp. 1-10). IEEE. Retrieved from http://ieeexplore.ieee.org/xpls/abs_all.jsp?arnumber $=4755627$

Kavanaugh, A. L., Reese, D. D., Carroll, J. M., \& Rosson, M. B. (2005). Weak ties in networked communities. The Information Society, 21(2), 119-131.

Kwak, H., Lee, C., Park, H., \& Moon, S. (2010). What is Twitter, a social network or a news media? In Proceedings of the 19th international conference on World wide web (pp. 591-60o). Retrieved from http://dl.acm.org/citation.cfm?id=1772751

Macià, M., \& García, I. (2016). Informal online communities and networks as a source of teacher professional development: A review. Teaching and Teacher Education, 55, 291-307.

McPherson, M., Smith-Lovin, L., \& Cook, J. M. (2001). Birds of a feather: Homophily in social networks. Annual Review of Sociology, 415-444.

Ranieri, M., Manca, S., \& Fini, A. (2012). Why (and how) do teachers engage in social networks? An exploratory study of professional use of Facebook and its implications for lifelong learning. British Journal of Educational Technology, 43(5), 754-769.

Ravenscroft, A., Schmidt, A., Cook, J., \& Bradley, C. (2012). Designing social media for informal learning and knowledge maturing in the digital workplace. Journal of Computer Assisted Learning, 28(3), 235-249. 
Schlager, M. S., Farooq, U., Fusco, J., Schank, P., \& Dwyer, N. (2009). Analyzing online teacher networks cyber networks require cyber research tools. Journal of Teacher Education, 6o(1), 86-100.

Smith, M. A., Rainie, L., Shneiderman, B., \& Himelboim, I. (2014). Mapping Twitter topic networks: From polarized crowds to community clusters. Pew Research Center, 2O. Retrieved from http://www.pewinternet.org/2014/02/20/part-2-conversational-archetypes-six-conversationand-group-network-structures-in-twitter/

Smith Risser, H. (2013). Virtual induction: A novice teacher's use of Twitter to form an informal mentoring network. Teaching and Teacher Education, 35, 25-33.

Smoot, M. E., Ono, K., Ruscheinski, J., Wang, P.-L., \& Ideker, T. (2011). Cytoscape 2.8: New features for data integration and network visualization. Bioinformatics, 27(3), 431-432.

Tajfel, H. (2010). Social identity and intergroup relations. Cambridge: Cambridge University Press.

Tseng, F.-C., \& Kuo, F.-Y. (2014). A study of social participation and knowledge sharing in the teachers' online professional community of practice. Computers \& Education, 72, 37-47.

Wenger, E., Trayner, B., \& de Laat, M. (2011). Promoting and assessing value creation in communities and networks: A conceptual framework. The Netherlands: Ruud de Moor Centrum. Retrieved from http://ebooks.narotama.ac.id/files/MIT\%2020102011\%20(pdf)/Promoting\%20and\%20assessing\%20value\%20creation\%20in\%20\%20communiti es\%20and\%20networks\%20-\%20a\%20conceptual\%20framework.pdf

Wesely, P. M. (2013). Investigating the community of practice of world language educators on Twitter. Journal of Teacher Education, 64(4), 305-318.

\section{Athabasca} University

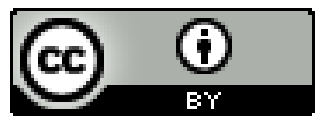

